\title{
USING GEOBIA AND DATA FUSION APPROACH FOR LAND USE AND LAND COVER MAPPING
}

\author{
Piotr WężyK ${ }^{1}$, PaweŁ Hawryło ${ }^{1}$, Marta Szostak ${ }^{1}$, Marcin Pierzchalski², \\ ROELAND DE KOK ${ }^{2}$ \\ ${ }^{1}$ Institute of Forest Resources Management, University of Agriculture in Kraków, Poland \\ ${ }^{2}$ ProGea Consulting, Faculty of Forestry Kraków, Poland
}

Manuscript received: November 26, 2015

Revised version: February 12, 2016

\begin{abstract}
Wężyk P., Hawryło P., Szostak M., Pierzchalski M., de KoK R., 2016. Using geobia and data fusion approach for land use and land cover mapping. Quaestiones Geographicae 35(1), Bogucki Wydawnictwo Naukowe, Poznań, pp. 93-104, 4 figs, 5 tables.

AвSTRACT: Land Use and Land Cover (LULC) maps play an important role in an environmental modelling, and for many years efforts have been made to improve and streamline the expensive mapping process. The aim of the study was to create LULC maps of three selected water catchment areas in South Poland using a Geographic Object-Based Image Analysis (GEOBIA) in order to highlight the advantages of this innovative, semi-automatic method of image analysis. The classification workflow included: multi-stage and multi-scale analyses based on a data fusion approach. Input data consisted mainly of BlackBridge (RapidEye) high resolution satellite imagery, although for distinguishing particular LULC classes, additional satellite images (LANDSAT TM5) and GIS-vector data were used. Accuracy assessment of GEOBIA classification results varied from 0.83 to 0.87 (Kappa), depending on the specific catchment area. The main recognized advantages of GEOBIA in the case study were: performing of multi-stage and multi-scale image classification using different features for specific LULC classes and the ability to using knowledge-based classification in conjunction with the data fusion approach in an efficient and reliable manner.
\end{abstract}

KEY WORDS: classification, hydrology, OBIA, RapidEye, SaLMaR

Corresponding author: Piotr Wężyk (p.wezyk@ur.krakow.pl)

\section{Introduction}

Cooperation within the EU concerns a large variety of transboundary topics, where the water management is a typical example and is at the centre of focus of the European Water Framework Directive (WFD). Implementing the WFD rules, requires innovative tools for river basin system assessment comprising the modelling and integrated analysis of hydrological and solute transport processes and related land use strategies (Flügel 2009). Those models required updated spatial information like LULC layers (GIS vector data) acquired from interpretation or classification of remote sensing data (aerial or satellite imageries). The wide range of classification methods of satellite data provides a great potential for rapid creation and revision of accurate LULC maps for large areas (Homer et al. 2004, Saadat et al. 2011). Image classification approaches are grouped into following categories (Lu and Weng 2007): per-pixel, subpixel, per-field, contextual classification, knowledge-based classification and combination of multiple classifiers as well. 
For many years, pixel-based classification methods have been used as a major tool for LULC mapping. Recently, an increasing interest can be observed in applying a Geographic Object-Based Image Analysis (GEOBIA), the method assigned by Lu and Weng (2007) to "per-field" group of classification algorithms. The main characteristic of GEOBIA is, that instead of analysing single pixels (like in traditional image classification methods) they are first grouped into segments (objects), more properly representing the real world entities (Baatz, Schape 2000). Image classification in GEOBIA method is analogous to human interpretation process where features like: brightness, shape, texture and context information are taken into consideration (Hay, Castilla 2006, Blaschke 2010).

For GEOBIA there are several synonyms like: Object-Based Image Analysis, object-based classification or object-oriented classification. Baatz et al. (2008) distinguished between more basic object-based classification approach and advanced object-oriented approach. The former can be considered as a two stage process of segmentation and then classification of created segments. In a such approach the initial segmentation process strongly influences the classification accuracy. In many cases it is very difficult to obtain satisfying segmentation results using the same parameters for all real word objects. Usually, it is necessary to perform different segmentations when trying to delineate e.g. single buildings and forest stands in the same image. To cope with this issue, the object-oriented approach can be applied. Baatz et al. (2008) described this method as a combination of a spiral model and a modular classification approach. In the spiral model, objects are repeatedly modified using various (sequential and alternating) segmentation and classification algorithms, until they represent the real world entities, as proper as possible. With the progress of the spiral model there is observed an increase in the level of details and the accuracy of classification. The modular approach means that classes are not classified simultaneously, like in traditional supervised pixel-based methods but can be run as a sequence, one after the other.

Among many benefits of using GEOBIA, the option to take advantage of the data fusion approach exists. There can be found many examples of successful utilizing the data fusion approach for LULC mapping. Willhauck et al. (2000) used SPOT multispectral images, aerial orthophotos and GIS-vector layers for forest classification. Molenaar (2001) applied data fusion for object-based land use classification of urban areas.

The basis of the GEOBIA process architecture relies less on image samples in order to train a classifier. More dominant is the known extensive list of crucial features, which are characteristic to the objects of interest. Feature selection in one of the crucial issue in image classification context being very important in case of supervised classification approaches (Xie et al. 2013), but even more fundamental for rule-based classification. Because of the availability of huge amount of object features in GEOBIA workflows, there is a need to distinguish the best ones for selected LULC classes (Nussbaum et al. 2006). A common issue of recent GEOBIA research is the topic of ontologies. Identification of best features for classification of selected LULC classes using defined set of geodata is a very important task in this context (Arvor et al. 2013).

The LULC mapping of catchments areas was a part of a complex GIS modelling performed in frame of a joined Polish-German research project called: SaLMaR (Sustainable Land and Water Management of Reservoir Catchments) implemented in 2012-2015. The main goal of the SaLMaR project is to develop Integrated Land and Water Resource Management (ILWRM), for all three selected Polish catchments, using J2000-S model (Fink et al. 2007). This model will be a tool for diagnosis, prognosis and optimization of the land use in various scenarios. During the SaLMaR project consistent criteria for: ecological, economic and structural region grow, will be developed, along with the optimization of its function.

The main goal of the study was to demonstrate how GEOBIA approach can be used for semi-automatic LULC classification based on different data sources like high and medium resolution satellite images and GIS vector layers. The secondary aim was to show that different classification strategies like: crisp and fuzzy logic classification, multiscale analysis, local processing, data fusion and knowledge-based classification can be integrated in the GEOBIA approach. 


\section{Material and methods}

\section{The study area}

The study area (Fig. 1) covers three water catchments, i.e.: Dzieckowice (A; 3.905 ha; Sola river), Dobczyce (B; 886 ha; Raba river) and Czorsztyn (C; 1.408 ha; Dunajec river) located in South Poland (Silesian and Malopolska Voivodeship; not necesarry) and partially in Slovakia (water catchment $\mathrm{C}$ ). The artificial lakes located in two first water catchment (A and B) areas are crucial, as drink water reservoirs for approx. 4 Mio of residents of two large urban agglomerations (Krakow and upper Silesia). The LULC mapping of those catchments areas was a part of SaLMaR project.
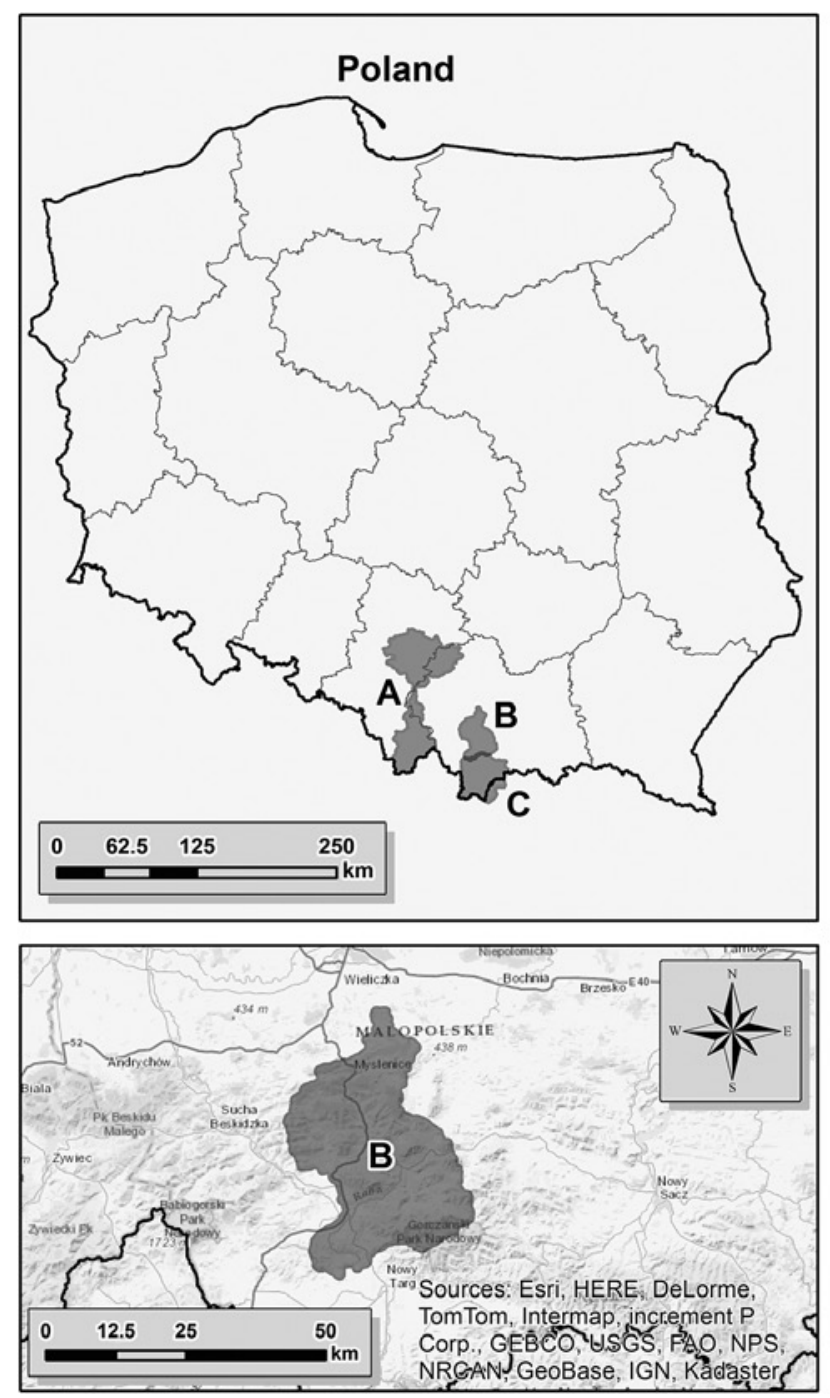

\section{Datasets}

The most important set of remote sensing data used for GEOBIA classification process involved BlackBridge RapidEye (BBRE) satellite imageries (GSD 5.0 m; 5 bands; RGB, Red-Edge; NIR) obtained at: 21.08.2011 (C), 26.08.2011(A), 27.08.2011(A, B, C) and 30.04.2012 (A). Since the analysed areas were covered by BBRE image only once, it was necessary to introduce additional satellite imageries, for distinguish between classes "Arable lands" (AL) and "Meadows and pastures" (MP). Thus several cloud free LANDSAT TM scenes (GSD 30.0 m; 7 spectral bands + PAN) from the period 2007-2011 were selected (Table 1). From LANDSAT TM images NDVI (Normalized Differential Vegetation Index)
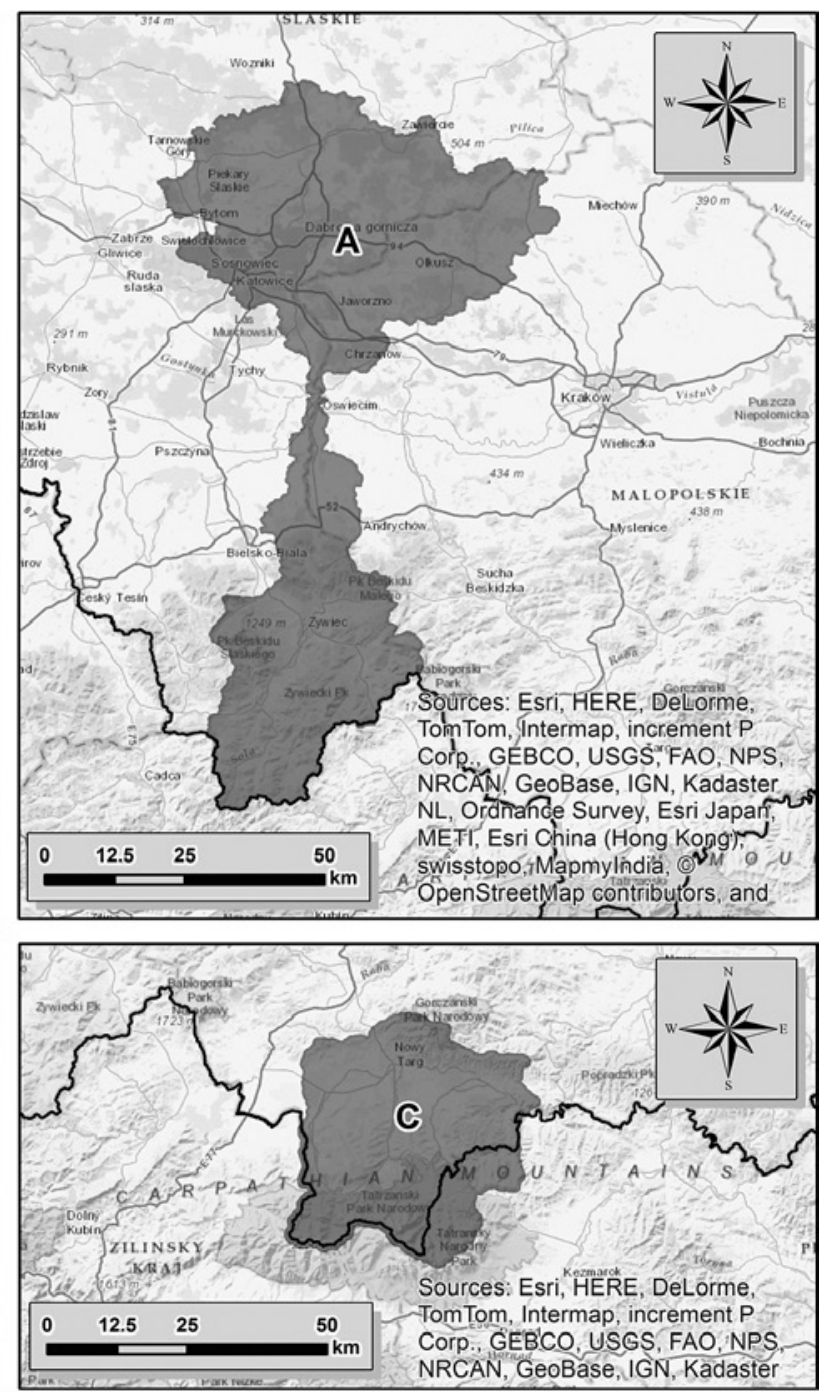

Fig. 1. The location of the analyzed water catchments in South Poland in frame of the SaLMaR project: A - Dzieckowice, B - Dobczyce, C - Czorsztyn (partially in Slovakia). 
Table 1. The most useful features identified and used in the GEOBIA workflow.

\begin{tabular}{|l|l|}
\hline \multicolumn{1}{|c|}{ LULC class } & \multicolumn{1}{c|}{ Features } \\
\hline Water (WA) & BBRE_NIR, BBRE_red, PCA_1, PCA_2, NDVI, area \\
\hline Roads (RO) & Existence of GIS-vector layer, NDVI, minimum length, maximum break \\
\hline Trees (TR) & BBRE_red, Red-edge_index, PCA_1, PCA_3, NDVI, area \\
\hline $\begin{array}{l}\text { Deciduous forest (DF), } \\
\text { Coniferous forest (CF) }\end{array}$ & BBRE_red, Red-edge_index, NDVI, Green NDVI \\
\hline $\begin{array}{l}\text { Built-up areas } \\
\text { dense (DB) } \\
\text { sparse(SB) }\end{array}$ & $\begin{array}{l}\text { relative area of sub-objects from class Buildings, number of sub- objects from } \\
\text { class Buildings, relative border to Built-up areas, distance to Built-up areas, } \\
\text { distance to Roads, area }\end{array}$ \\
\hline $\begin{array}{l}\text { Arable lands (AL)/Meadows } \\
\text { and pastures (MP), Bare lands } \\
\text { (BL) }\end{array}$ & $\begin{array}{l}\text { BBRE_red, NDVI, five NDVI layers calculated from LANDSAT TM (LANDSAT } \\
\text { 5) scenes (acquired at: 09 March 2011; 27 August 2011; 12 June 2010; 21 August } \\
\text { 2009 and, 03 May 2007) }\end{array}$ \\
\hline Wetlands (WE) & distance to class Water (WA) \\
\hline Rocks (RC) & NDVI, Elevation from SRTM DEM model \\
\hline
\end{tabular}

layers were calculated and used for classification as additional layers. As a pre-processing step, the georeferencing of the satellite images to Polish coordinate system (PL-1992; EPSG:2180), based on aerial orthophotomaps available by Web Map Service (http:/ / mapy.geoportal.gov.pl) was performed using ArcGIS 10.0. For the BBRE images the Principal Component Analysis (PCA) was carried out using the ERDAS Imagine 2011 software. The first three PCA components were subsequently used in segmentation and classification process. For classification of "Roads" (RO) and "Built-up areas" additional GIS-vector reference data from the Polish Geographical Topographic Geodatabase (GBDOT) were used. The accuracy of vector data (buildings and roads) corresponds to the level of 1:10,000 map scale. The SRTM Digital Elevation Model (DEM) was used to improve classification of class "Rocks" (RC).

\section{Classification workflow}

In the presented study, the eCognition Developer (Trimble GeoSpatial) software was used to perform GEOBIA rule-based classification. Thanks to using modular programming language - Cognition Network Language (CNL), the software enabled very flexible and efficient design of the multi-stage rule-based classification workflow. The GEOBIA design using CNL allows a very flexible but also a complex architecture of the process flow. In presented study the multi-stage rule-based classification was performed. The water catchments areas slightly differed from each other (geomorphology, vegetation, etc.) and also BBRE scenes from different time was used for these areas. Therefore it was necessary to modify classification rules (rule- sets) for each of analysed catchment. The GEOBIA classification for one selected catchment - Czorsztyn (C), was chosen as an example how crucial features are integrated in the rule-set. However, the classification results and accuracy assessment are presented by the authors for all catchments. Although the rule-sets themselves might differ slightly due to differences in the input imagery, crucial features remain the same and can be transferable (to other rule-sets and/or areas). The most useful features identified in the study as appropriate for GEOBIA are presented in Table 1.

Rule sets are rarely fully transferable (Arvor et al. 2013) thus the authors decided to concentrate more on general presentation of GEOBIA workflow giving the sequence of performed processes and list of used features, than on exact threshold values for features, which can differ in other area. Besides automatic rule-based classification, two additional steps was added - manual editing and final reshaping and smoothing of objects. Manual editing process involved visual checking of the results and corrections in case of explicit errors (especially for problematic classes: Rocks and Wetlands). After that, the final smoothing and reshaping was done, accordingly to the LULC map requirements defined by the customer like minimum area: agriculture $>0.5$ ha; forest $>0.1$ ha. Additional conditions for class "Roads" are described further in the paper. Accuracy assessment was performed by operator visual onscreen check for each catchment area separately based on 20 randomly selected points per every LULC class. As a reference data, the digital aerial 


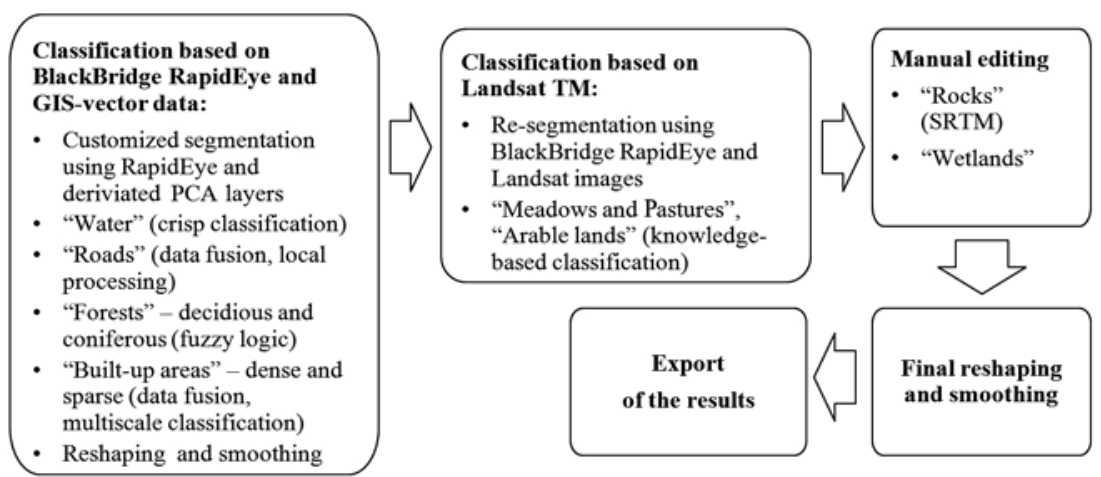

Fig. 2. GEOBIA workflow for the selected Czorsztyn (C) water catchment area.

orthophotomaps (available through WMS) were used. The overview of the classification workflow is presented in Figure 2.

\section{Segmentation Process}

For the image segmentation purposes the customized algorithm was created using CNL. In an initial step the multiresolution segmentation (Baatz, Schape 2000) was performed using following parameters: Scale $=50$, Shape $=$ 0.2 , Compactness $=0.8$. As input for segmentation, following layers were used: four bands of BBRE image - BBRE_green (weight 1), BBRE_red (weight 2), BBRE_red-edge (weight 2), BBRE_ NIR (weight 2); PCA_1 - first band (weight 2), PCA_2 - second band (weight 1). The PCA bands were used in segmentation as raster layers which provide information of pixels variability. It helps to achieve segments which better represent the real world objects comparing to segmentation based only on the original RapidEye bands. All raster layers were recalculated to 16 bit range values. After the initial segmentation, adjacent segments were merged if following conditions were fulfilled: difference in NDVI $<0.1$, difference in Red-edge_index $<0.05$, difference in spectral bands and PCA $<300$. After that, the segments were divided into two subsets. Segments with NDVI $>=0.4$ were classified to temporary class "Vegetation" and merging of adjacent segments was performed separately for each sub-set with similar conditions as earlier. The spectral difference for BBRE bands and PCA was raised to 700 . Merging of neighbour segments was run as an iterative process in the loop. In each iteration of the loop, the spectral difference for BBRE bands and PCA layers was growing by 10 , until it achieved the value of 300 or 700 accordingly. The Red-edge_index feature was calculated as: $\log 10$ (1/BBRE_red-edge). At the end of described process, all of the objects were assigned back to unclassified objects. Created segments were a base for further classification steps, although reshaping algorithms improving class boundaries were performed if necessary.

\section{Crisp classification and local processing}

The GEOBIA classification started from the class "Water" (WA). In general, the crisp classification approach was used, utilizing several object features (Table 1). Crisp classification means, that objects were assigned to the class using defined thresholds and Boolean logic $(0,1)$. Classification was based on previously created segments, but finally the objects from class "Water" were slightly reshaped. The objects were extended to neighbour pixels with value of BBRE_NIR band $<4000$. The process was similar to known GIS spatial analysis called "buffer", however processing was conditioned not only by a distance, but also by spectral values of neighbouring pixels. Such an approach can be recognized as a "local processing" connected to idea of spiral model of classification (Baatz et al. 2008). Usually, creation of proper segments for all LULC classes is very demanding and often not possible, therefore once created segments have to be reshaped until they create "meaningful objects" and represent real world objects in best way (Blaschke et al. 2014). Concept of local processing was also used for classifying the class "Roads". In the first step, GIS vector data (Esri Shapefile) was used and pixels intersected with the shapefile were classified to "Roads". For the hydrologic modelling purposes 
in frame of SaLMaR project, there was a demand to classify only roads of higher order, omitting small agricultural and forest tracks and patches. It was assumed, that in the final LULC map, the class "Roads" should concern only areas without vegetation cover. It was achieved by removing pixels with NDVI $>0.4$ from the class "Roads". Additional condition was, that minimum length of $\operatorname{Road}>50 \mathrm{~m}$.

\section{Fuzzy Logic Concept}

As stated before, in GEOBIA workflow many methods can be integrated. For classification of forest areas, crisp classification was carried out, and after that, for distinguishing process between "Coniferous Forest" (CF) and "Deciduous Forest' (DF), the fuzzy logic concept was applied. In the first step to create a general class "Forest", several features were used (Table 1). The reasoning in fuzzy logic is approximated rather than precise classification. The method is based on fuzzy set theory (Hofmann et al. 2011). According to this concept, one object can belong to several classes with different level of probability. Membership functions are created for different features, and membership values may range from 0 to 1 . Thus fuzzy rules were created using additional features (Table 1). To calculate Green_NDVI, the Green band of BBRE instead of Red band was used in NDVI formula. Finally, from classes CF and DF, a class "Trees" (TR) was created for areas smaller than $0.1 \mathrm{ha}$, accordingly to Polish regulations (the minimum of forest area).

\section{Multi-Scale And Knowledge-Based Classification}

Based on multi-scale concept (Burnett, Blaschke 2003), to classify single buildings using available GIS-vector data (Fig. 3) the additional levels of objects were created. Since such a level of details (single buildings) was not appropriate for the purposes of the SaLMaR project, there was a need to create generalized classes like: "Dense built-up areas" (DB) and "Sparse built-up areas" (SB). Hierarchy of segment levels is characterized by the rule that borders of super-objects always exist in level of sub-objects (Benz et al. 2004). Using three object levels in different scales, it was possible to use additional information like: relative area of sub-objects from class Buildings or number of Buildings in object. Additionally contextual features like distance to "Built-up areas" or distance to "Roads" were used (Table 1).

Very demanding classes for classification were: "Arable lands" (AL) and "Meadows and pastures" (MP). Distinguishing them based on BBRE image from single time period was not possible, because AL with vegetation cover, have very similar spectral characteristics to MP. The AL class is characterized by seasonal spectral dynamics which are caused by agriculture activity. Based on this knowledge, the following procedure was carried out. In the first step, objects which potentially belongs to mentioned LULC classes were classified into temporary class "Agriculture" using only BBRE images.

In the second step, this pool of segments was divided into target classes based on NDVI values calculated from additional LANDSAT TM images. For class "Agriculture" multi-resolution segmentation was performed using spectral bands of: BBRE and LANDSAT TM - NIR, Red and Green as well. In case of Czorsztyn (C) water catchment, five additional LANDSAT images from different periods were used (Table 1), so the number of input bands for segmentation amounted to 18. For all bands weight $=1$ was used, excepting NIR and Red band of BBRE (weight: 2). Following segmentation parameters were used:
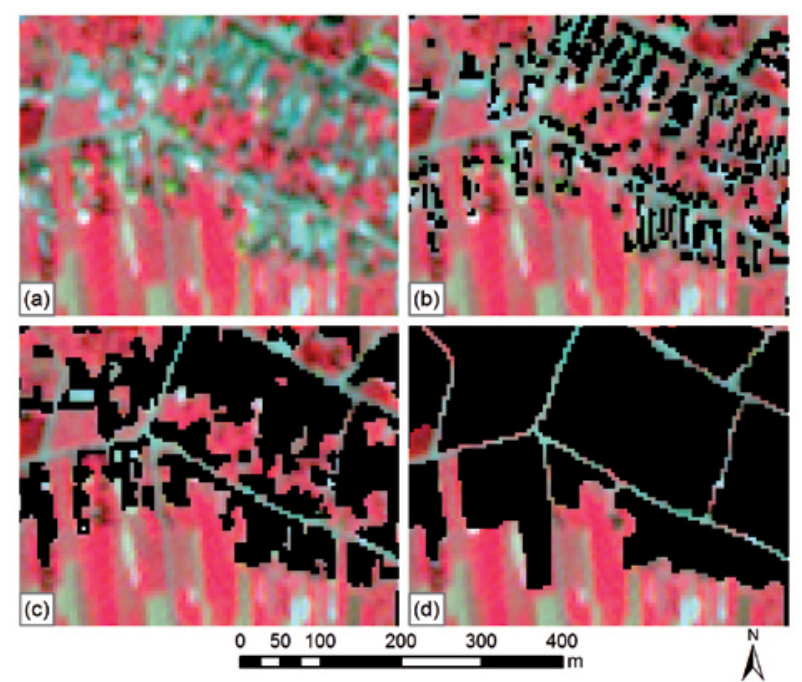

Fig. 3. Classification of "Sparse built-up areas" using BBRE (a) and GIS-vector data performed in three steps: classification based on vector data (b), classification of objects on higher scale level (c), and final generalization using the highest scale of objects (d). 

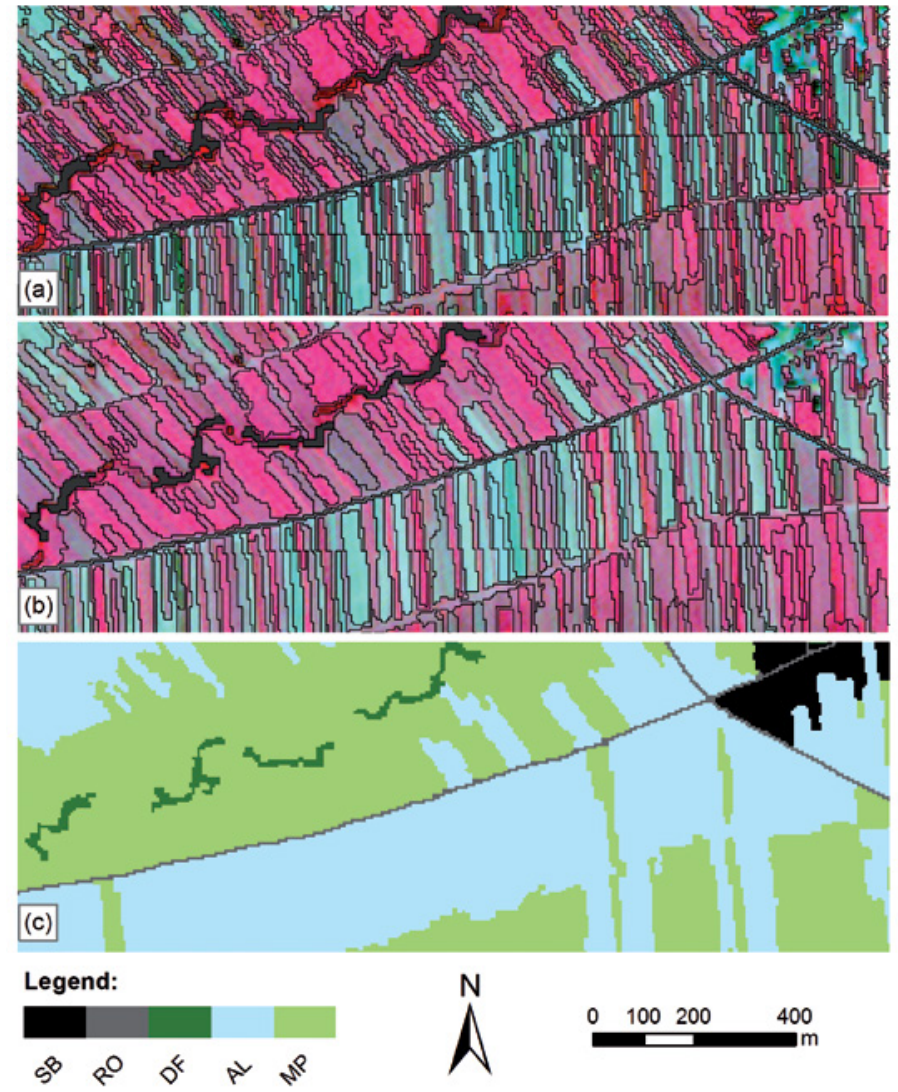

Fig. 4. Classification of "Meadows and Pastures" (MP) and "Arable Lands" (AL) using data fusion concept and knowledge-based approach: (a) - segmentation using BBRE image, (b) - improved segmentation using BBRE and LANDSAT TM scenes, and final results of classification based on NDVI layers calculated from LANDSAT TM images (c).

Scale $=60$, Shape $=0.4$, Compactness $=0.9$. It was assumed, that if certain object was characterized by high value of NDVI $>=0.5$ in the selected moments of vegetation period, the object should belong to the MP class, not to AL (Fig. 4). This steep can be recognized as "knowledge-based classification", because operator is introducing into classification rules, the knowledge about agriculture model and characteristic features of crops phenology stage.

\section{Results}

Based on GEOBIA approach, the LULC maps for three selected water catchment areas were created. The classification results with achieved overall accuracies and Kappa coefficients for each catchment are presented below (Table 2). Results of accuracy assessment are presented in error matrices with given Producer Accuracy (PA) and User Accuracy (UA) for each class (Table 3, 4).
To be able to carry out a hydrological modelling within the SaLMaR project it was necessary to generate a new LULC map, because the existing reference information (topographical data base) were not-updated and therefore not adequate for such purposes. The existing for the study area, CORINE Land Cover (CLC) GIS layers from year 2006, are very generalized and not up-to-date, thus did not guarantee achievement of reliable results of hydrologic modelling. From the other hand, there are also very accurate vector data in 1:10,000 scale but only for selected classes of objects (roads and buildings). These data are too detailed for hydrological analysis and had to been generalized. In Poland, there are also available vector data in 1:10,000 scale, concerning forest cover owned by Polish State Forest National Holding. The problem with forest digital maps is, that many secondary forest succession areas on abandoned agriculture parcels are not included there, but are still treated as an agriculture land. Additionally there is a lack of detailed forest 
Table 2. The LULC classes distribution in the analysed catchment areas obtained from GEOBIA classification.

\begin{tabular}{|c|c|c|c|c|c|c|}
\hline \multirow[t]{2}{*}{$\begin{array}{c}\text { LULC } \\
\text { class }\end{array}$} & \multicolumn{2}{|c|}{$\begin{array}{c}\text { Dzieckowice } \\
(\mathrm{A} ; \text { Sola river }) \\
\text { Kappa }=0,83 \\
\text { Overall accuracy }=85 \%\end{array}$} & \multicolumn{2}{|c|}{$\begin{array}{c}\text { Dobczyce } \\
\text { (B; Raba river) } \\
\text { Kappa }=0,87 \\
\text { Overall accuracy }=88 \%\end{array}$} & \multicolumn{2}{|c|}{$\begin{array}{c}\text { Czorsztyn } \\
\text { (C; Dunajec river) } \\
\text { Kappa }=0,83 \\
\text { Overall accuracy }=85 \%\end{array}$} \\
\hline & Area $\left[\mathrm{km}^{2}\right]$ & Area[\%] & Area $\left[\mathrm{km}^{2}\right]$ & Area [\%] & Area $\left[\mathrm{km}^{2}\right]$ & Area [\%] \\
\hline SB & 73.04 & 1.87 & 27.84 & 3.14 & 9.66 & 0.69 \\
\hline DB & 276.21 & 7.07 & 21.51 & 2.43 & 52.54 & 3.73 \\
\hline $\mathrm{RO}$ & 61.73 & 1.58 & 11.23 & 1.27 & 7.75 & 0.55 \\
\hline $\mathrm{CF}$ & 974.53 & 24.95 & 257.85 & 29.08 & 529.21 & 37.58 \\
\hline DF & 772.79 & 19.79 & 217.63 & 24.55 & 133.02 & 9.45 \\
\hline TR & 32.27 & 0.83 & 4.38 & 0.49 & 6.55 & 0.47 \\
\hline $\mathrm{AL}$ & 1075.43 & 27.54 & 152.05 & 17.15 & 51.30 & 3.64 \\
\hline $\mathrm{MP}$ & 530.51 & 13.58 & 179.82 & 20.28 & 541.68 & 38.47 \\
\hline $\mathrm{BL}$ & 50.87 & 1.30 & 4.47 & 0.50 & 5.51 & 0.39 \\
\hline WA & 58.13 & 1.49 & 9.86 & 1.11 & 16.71 & 1.19 \\
\hline WE & 0.00 & 0.00 & 0.00 & 0.00 & 7.18 & 0.51 \\
\hline $\mathrm{RC}$ & 0.00 & 0.00 & 0.00 & 0.00 & 46.98 & 3.34 \\
\hline
\end{tabular}

maps and forest inventory data for private woodlands (approx. 50\% of forest in Czorsztyn catchment area are private). In order to better understand the differences between created LULC map and Corine Land Cover 2006 (CLC) data, there are given some comparisons for the Czorsztyn catchment below.

In case of CLC class 311 (Broadleaved forest), only $59.0 \%$ of the area was covered by DF in fact. The remaining area was covered, among the others by CF (20.1\%), BL (8.5\%) and MP (5.8\%). Better coincidence was observed for the class 312
(Coniferous forest). In that case almost 83.5\% were covered by $\mathrm{CF}, 9.2 \%$ by DF and $5.9 \%$ by MP. In CLC legend also class also "Mixed forest" (313) can by find. In the GEOBIA legend mixed forests were not defined by authors, and finally $54.2 \%$ of class 313 was covered by CF, $41 \%$ by DF, and the rest of the area by another classes. In CLC 2006 there is defined the class 122 - "Road and rail networks and associated land". For analysed Czorsztyn catchment area, this CLC class (122) was not present, while GEOBIA resulted in 7.75 $\mathrm{km}^{2}$. Relatively high coincidence was observed in

Table 3. Error matrix for the Czorsztyn water catchment area (1.408 ha).

\begin{tabular}{|c|c|c|c|c|c|c|c|c|c|c|c|c|c|c|c|}
\hline \multicolumn{16}{|c|}{ Classification results } \\
\hline \multirow{15}{*}{ 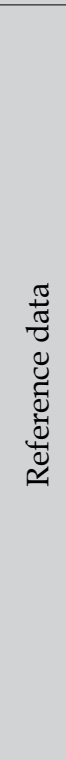 } & $\begin{array}{l}\text { Class } \\
\text { name }\end{array}$ & SB & DB & RO & $\mathrm{CF}$ & DF & TR & $\mathrm{AL}$ & MP & BL & WA & WE & $\mathrm{RC}$ & SUM & PA \\
\hline & SB & 16 & 4 & 0 & 0 & 0 & 0 & 1 & 1 & 1 & 0 & 0 & 0 & 23 & 69 \\
\hline & DB & 0 & 15 & 0 & 0 & 0 & 0 & 0 & 0 & 0 & 0 & 0 & 0 & 15 & 100 \\
\hline & $\mathrm{RO}$ & 0 & 0 & 20 & 0 & 0 & 0 & 0 & 0 & 0 & 0 & 0 & 0 & 20 & 100 \\
\hline & $\mathrm{CF}$ & 0 & 0 & 0 & 17 & 4 & 0 & 0 & 0 & 2 & 0 & 1 & 0 & 24 & 70 \\
\hline & DF & 0 & 0 & 0 & 2 & 16 & 0 & 0 & 0 & 1 & 1 & 3 & 0 & 23 & 69 \\
\hline & TR & 0 & 0 & 0 & 0 & 0 & 19 & 0 & 1 & 0 & 0 & 0 & 0 & 20 & 95 \\
\hline & $\mathrm{AL}$ & 0 & 0 & 0 & 0 & 0 & 0 & 17 & 0 & 0 & 0 & 0 & 0 & 17 & 100 \\
\hline & MP & 4 & 1 & 0 & 1 & 0 & 0 & 2 & 18 & 0 & 0 & 2 & 3 & 31 & 58 \\
\hline & BL & 0 & 0 & 0 & 0 & 0 & 0 & 0 & 0 & 16 & 0 & 0 & 0 & 16 & 100 \\
\hline & WA & 0 & 0 & 0 & 0 & 0 & 0 & 0 & 0 & 0 & 19 & 0 & 0 & 19 & 100 \\
\hline & WE & 0 & 0 & 0 & 0 & 0 & 0 & 0 & 0 & 0 & 0 & 14 & 0 & 14 & 100 \\
\hline & $\mathrm{RC}$ & 0 & 0 & 0 & 0 & 0 & 1 & 0 & 0 & 0 & 0 & 0 & 17 & 18 & 94 \\
\hline & SUM & 20 & 20 & 20 & 20 & 20 & 20 & 20 & 20 & 20 & 20 & 20 & 20 & 204 & \\
\hline & UA & 80 & 75 & 100 & 85 & 80 & 95 & 85 & 90 & 80 & 95 & 70 & 85 & & \\
\hline
\end{tabular}


Table 4. Error matrix for the Dobczyce water catchment area (886 ha).

\begin{tabular}{|c|c|c|c|c|c|c|c|c|c|c|c|c|c|}
\hline \multicolumn{14}{|c|}{ Classification results } \\
\hline \multirow{13}{*}{ 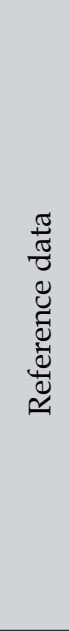 } & $\begin{array}{l}\text { Class } \\
\text { name }\end{array}$ & SB & DB & $\mathrm{RO}$ & $\mathrm{CF}$ & $\mathrm{DF}$ & TR & AL & MP & BL & WA & SUM & PA \\
\hline & SB & 18 & 0 & 1 & 0 & 0 & 0 & 1 & 0 & 4 & 1 & 25 & 72 \\
\hline & DB & 0 & 20 & 0 & 0 & 0 & 0 & 0 & 0 & 0 & 0 & 20 & 100 \\
\hline & RO & 1 & 0 & 18 & 0 & 0 & 0 & 0 & 0 & 0 & 0 & 19 & 95 \\
\hline & CF & 0 & 0 & 0 & 17 & 2 & 0 & 1 & 0 & 0 & 0 & 20 & 85 \\
\hline & DF & 0 & 0 & 0 & 3 & 14 & 0 & 1 & 0 & 0 & 0 & 18 & 78 \\
\hline & TR & 0 & 0 & 0 & 0 & 1 & 18 & 0 & 0 & 0 & 0 & 19 & 95 \\
\hline & $\mathrm{AL}$ & 1 & 0 & 0 & 0 & 0 & 0 & 17 & 0 & 2 & 0 & 20 & 85 \\
\hline & MP & 0 & 0 & 1 & 0 & 3 & 2 & 0 & 17 & 0 & 0 & 23 & 74 \\
\hline & BL & 0 & 0 & 0 & 0 & 0 & 0 & 0 & 3 & 14 & 1 & 18 & 78 \\
\hline & WA & 0 & 0 & 0 & 0 & 0 & 0 & 0 & 0 & 0 & 18 & 18 & 100 \\
\hline & SUM & 20 & 20 & 20 & 20 & 20 & 20 & 20 & 20 & 20 & 20 & 171 & \\
\hline & UA & 90 & 85 & 85 & 70 & 70 & 85 & 90 & 90 & 100 & 90 & & \\
\hline
\end{tabular}

Table 5. Error matrix for the Dzieckowice water catchment area (3.905 ha).

\begin{tabular}{|c|c|c|c|c|c|c|c|c|c|c|c|c|c|}
\hline \multicolumn{14}{|c|}{ Classification results } \\
\hline \multirow{13}{*}{ 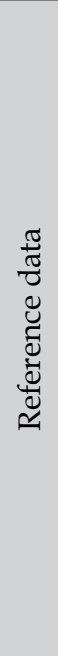 } & $\begin{array}{l}\text { Class } \\
\text { name }\end{array}$ & SB & DB & $\mathrm{RO}$ & $\mathrm{CF}$ & DF & TR & $\mathrm{AL}$ & MP & BL & WA & SUM & PA \\
\hline & SB & 18 & 2 & 0 & 0 & 1 & 0 & 0 & 0 & 0 & 0 & 21 & 86 \\
\hline & DB & 0 & 16 & 1 & 0 & 0 & 0 & 0 & 0 & 3 & 1 & 21 & 76 \\
\hline & RO & 1 & 0 & 18 & 0 & 0 & 0 & 0 & 0 & 0 & 0 & 19 & 95 \\
\hline & $\mathrm{CF}$ & 0 & 0 & 0 & 16 & 3 & 2 & 0 & 0 & 0 & 0 & 21 & 76 \\
\hline & DF & 0 & 0 & 0 & 3 & 13 & 1 & 0 & 0 & 0 & 0 & 17 & 76 \\
\hline & TR & 0 & 0 & 0 & 0 & 1 & 17 & 0 & 1 & 0 & 0 & 19 & 89 \\
\hline & $\mathrm{AL}$ & 0 & 0 & 0 & 0 & 0 & 0 & 18 & 1 & 0 & 0 & 19 & 95 \\
\hline & MP & 1 & 0 & 0 & 1 & 2 & 0 & 2 & 18 & 0 & 0 & 24 & 75 \\
\hline & $\mathrm{BL}$ & 0 & 2 & 1 & 0 & 0 & 0 & 0 & 0 & 17 & 0 & 20 & 85 \\
\hline & WA & 0 & 0 & 0 & 0 & 0 & 0 & 0 & 0 & 0 & 19 & 19 & 100 \\
\hline & SUM & 20 & 20 & 20 & 20 & 20 & 20 & 20 & 20 & 20 & 20 & 170 & \\
\hline & UA & 90 & 80 & 90 & 80 & 65 & 85 & 90 & 90 & 85 & 95 & & \\
\hline
\end{tabular}

case of CLC class 332 - "Bare rocks", where 74.2\% was covered by RC. stability of these features that guarantee the transferability of the classification strategies.

The creation of selected LULC classes as presented in this study can be used as proof of concept of sequential classification. For the classes: $\mathrm{SB}, \mathrm{DB}, \mathrm{RO}, \mathrm{AL}$ and MP different input data and different sequences of segmentation, classification and generalization where used.

\section{Discussion}

The GEOBIA and its rule based approach might be subject to a lack of transferability (Salehi et al. 2013). Although the rules themselves are needed to be adapted to the classification tasks, the core of these rules are the choice of essential features which in themselves are remaining stable throughout season and scale. The presented study clarify that certain features are linked to certain classes. The spectral variability between MP and AL in multi-temporal LANDSAT TM imagery is a reliable feature to distinguish these classes regardless the rule-set developed for 
them and the sequence in which these features are used.

The topic of using additional vector data for image classification, was early highlighted by (Hay, Castilla 2006) as one of main issues in development of GEOBIA. Smith and Morton (2010) remarked, that today in most environmental or geographical analysis it is rarely to begun on a blank canvas and additional spatial data should be used whenever are available. They gave an example of integration of vector land parcel data with LANDSAT TM images for creation of United Kingdom national land-cover map. Tiede et al. (2010) also used data fusion approach of cadastral vector data and SPOT images for biotope complexes modelling. Presented study is an example of successful integration of remote sensing images and GIS-vector data and for classification of $\mathrm{RO}$ and SB/DB.

It is important to notice that different classification strategies were used in parallel in one LULC mapping project. The results of the presented study indicates that GEOBIA approach, instead of considering as one of 63 separated classification method (Lu, Weng 2007), should be rather treated as the method where many classification approaches from different categories can be integrated and used.

When analysing the results of the accuracy assessment and comparing to results achieved by other authors (Varga et al. 2014), few remarks should be taken into account. First of all, the LULC classes were defined particularly for the SaLMaR project purposes and therefore may differ from standard definitions (like CLC 2006). For example, in the case of RO class, there was an assumption, that if in the road there are pixels representing vegetation on distance $<50$ meters, those pixels should be classified into class RO. If consider only the spectral information the pixels would be classified to one of the classes with vegetation (MP, DF, CF, TR or AL). A similar situation occurred for example, if the point examined during the accuracy assessment has been selected in a small meadow (area $<0.5$ ha) surrounded by deciduous forest. According to MP class definition (minimum area $>=0.5 \mathrm{ha}$ ) the pixel were classified to DC not MP, and it should be considered as a correct classification, although spectral information showed something different. Although, still in this paper conventions on Kappa value are followed, in a multi-stage approach a specific quality assessment might be required for each separated stage in a per class/categorical classification procedure. Developments on alternatives to Kappa based accuracy assessments are still part of expert discussion (Schöpfer, Lang 2006, Marinho et al. 2012).

The additional amounts of GIS and RS data makes it likely that a whole range of techniques will be integrated in a multi-stage classification. A compilation of best practises would then shift away from best classifier or best segmentation algorithm, to an object-class focussed approach with emphasis on best characteristic features per object-class. For each given categories or class in the legend a separated strategy will become available as part of an overall GEOBIA approach where also classic pixel based approaches still could be an essential part of selected sub-categories (using edges or contrast).

\section{Conclusions}

Very high dynamic of LULC structure changes in South Poland are highly correlated and associated with socio-economic changes happened during last 25 years of fast developing of this country. These quick and wide changes often cause the obsolescence of geospatial information used as a reference by many offices and policy makers. Those data are base for commonly DSS systems responsible for maintaining a sustainable economy and monitoring landscape and the environment components, including water quality in river catchments, underlying proper functioning of large urban agglomerations like Silesia or Krakow area. In order to keep updated spatial information in reference databases, and thus proper environmental management, it is essential to use appropriate (fast, objective and transferable) classification methods. As showed in the presented study, the GEOBIA concept, recognized as a new paradigm of remote sensing (Blaschke et al. 2014), has many advantages which can be efficiently utilized in medium and wide-areas LULC mapping projects. Its implementation in conjunction with raster and vector data fusion leads to savings in time and money. Considering already existing huge amount of geodata and upcoming EO missions (e.g. NASA 
LDCM, ESA Sentinel-2) together with growing needs of the information society, GEOBIA tends to be a reliable method to meet these challenges and maintain the up-to-date reference databases.

The studies carried out in the project on three mountainous catchments, providing potable water for several million of the residents in the Silesian agglomeration and Cracow. They make very important anti-flood protection for these areas. The studies proved clearly that the application of proper GIS models for these regions to monitor the state of natural environment requires continuous supplementation of the bases of spatial data into up-to-date information layers. The obtained results confirmed the existing differences in the participation of definite classes LULC, not only between catchments, but first of all, compared to the existing bases of reference data CORINE or BDOT. Present geodata for vast areas are now obtained in a semi-automatic way of the GEOBIA classification, using multi-scale, multi-source and multi-spectral satellite images with the RedEdge channel and Near InfraRed as well as derivative images such as PCA or edge filters and various methods of GEOBIA approach. Other methods applied so far in the papers of this type, such as photo-interpretation and manual vectorization of airborne photos, even if carried out by experienced experts, have always an element of subjectivity and are unchangeably dependent on the data of obtaining images and very time and cost-consuming. The classification of satellite images with a pixel-based method, on the other hand, requires selecting training areas, which are not universal for changeable environmental conditions (phenology, health status) or anthropogenic impact (e.g. clear cuts, use of agricultural land). Making the rules of segmentation and classification GEOBIA (rule-sets) allows quick modification and adjustment, which provides universal character of similar areas close in the spectral characteristic and terrain resolution of satellite images. The approaching quickly era of nanosatellites (e.g., Plant Labs) offering the daily imaging of the continents with spectral resolution of 4 channels and terrain resolution below several metres, causes the amount of image information, will increase incomparably to present possibilities of obtaining data, limited mainly by low time resolution and meteorological conditions. The only direction of the use of this information in terms of the updating reference databases, and consequently GIS models describing the environment, will be their mass processing with automatic GEOBIA methods.

\section{Acknowledgments}

Research was done in frame the project "Sustainable Land Water Management of Reservoir Catchments" (SaLMaR) - WPN/1/2012 (NCBiR).

The authors would like to thank to the reviewers for all of very valuable and helpful comments.

\section{References}

Arvor D., Durieux L., Andrés S., Laporte M.A., 2013. Advances in Geographic Object-Based Image Analysis with Ontologies: A Review of Main Contributions and Limitations from a Remote Sensing Perspective. ISPRS Journal of Photogrammetry and Remote Sensing 82 (August): 125-137. DOI: 10.1016/j.isprsjprs.2013.05.003.

Baatz M., Hoffmann C., Willhauck G., 2008. Progressing from Object-Based to Object-Oriented Image Analysis. In: Blaschke T., Lang S., Hay G.J. (eds), Object-Based Image Analysis: Spatial Concepts for Knowledge-Driven Remote Sensing Applications, 1st ed., 29-42. Springer, Berlin-Heidelberg.

Baatz M., Schape A., 2000. Multiresolution Segmentation: An Optimization Approach for High Quality Multi-Scale Image Segmentation. Journal of Photogrammetry and Remote Sensing 58(3-4): 12-23.

Benz U., Hofmann P., Willhauck G., Lingenfelder I., Heynen M., 2004. Multi-Resolution, Object-Oriented Fuzzy Analysis of Remote Sensing Data for GIS-Ready Information. ISPRS Journal of Photogrammetry and Remote Sensing 58(3-4): 239-258. DOI: 10.1016/j.isprsjprs.2003.10.002.

Blaschke T., Hay G.J., Kelly M., Lang S., Hofmann P., Addink E., Queiroz Feitosa R., et al., 2014. Geographic Object-Based Image Analysis - Towards a New Paradigm. ISPRS Journal of Photogrammetry and Remote Sensing 87 (January): 180-191. DOI: 10.1016/j.isprsjprs.2013.09.014.

Blaschke T., 2010. Object Based Image Analysis for Remote Sensing. ISPRS Journal of Photogrammetry and Remote Sensing 65(1): 2-16. DOI: 10.1016/j.isprsjprs.2009.06.004.

Burnett C., Blaschke T., 2003. A Multi-Scale Segmentation/ object Relationship Modelling Methodology for Landscape Analysis. Ecological Modelling 168(3): 233-49. DOI: 10.1016/S0304-3800(03)00139-X.

Fink M., Krause P., Kralisch S., Bende-Michl U., Flügel WA., 2007. Development and Application of the Modelling System J2000-S for the EU-Water Framework Directive. Advances in Geosciences 11: 123-30.

Flügel A.W., 2009. Applied Geoinformatics for Sustainable IWRM and Climate Change Impact Analysis. Technology, Resource Management \& Development 6: 57-85.

Hay G.J., Castilla G., 2006. Object-Based Image Analysis: Strengths, Weaknesses, Opportunities and Threats (SWOT). The International Archives of the Photogrammetry, Remote Sensing and Spatial Information Sciences 36: 4. 
Hofmann P., Blaschke T., Strobl J., 2011. Quantifying the Robustness of Fuzzy Rule Sets in Object-Based Image Analysis. International Journal of Remote Sensing 32(22): 37-41.

Homer C., Huang C., Yang L., Wylie B., Coan M., 2004. Development of a 2001 National Land-Cover Database for the United States. Photogrammetric Engineering \& Remote Sensing 70(7): 829-840. DOI: 10.14358/PERS.70.7.829.

Lu D., Weng Q., 2007. A Survey of Image Classification Methods and Techniques for Improving Classification Performance. International Journal of Remote Sensing 28(5): 823-870. DOI: 10.1080/01431160600746456.

Marinho E., Fasbender D., de Kok R., 2012. Spatial Assessment of Categorical Maps: A Proposed Framework. In: Proceedings of the 4th GEOBIA, 602-607. Rio de Janeiro, Brazil: São José dos Campos: INPE.

Molenaar M., 2001. Hierarchical Object-Based Image Analysis of High-Resolution Imagery for Urban Land Use Classification. In: IEEE/ISPRS Joint Workshop on Remote Sensing and Data Fusion over Urban Area, 35-39. Rome, University of Rome LA Sapienza: IEEE. DOI: 10.1109/ DFUA.2001.985721.

Nussbaum S., Niemeyer I., Canty M.J., 2006. SEaTH - A New Tool for Automated Feature Extraction in the Context of Object-Oriented Image Analysis. International Archives of the Photogrammetry, Remote Sensing and Spatial Information Sciences XXXVI-4/C4.

Saadat H., Adamowski J., Bonnell R., Sharifi F., Namdar M., Ale-Ebrahim S., 2011. Land Use and Land Cover Classification over a Large Area in Iran Based on Single Date Analysis of Satellite Imagery. ISPRS Journal of Photogrammetry and Remote Sensing 66(5): 608-619. DOI: 10.1016/j. isprsjprs.2011.04.001.
Salehi B., Zhang Y., Zhong M., 2013. A Combined Objectand Pixel-Based Image Analysis Framework for Urban Land Cover Classification of VHR Imagery. Photogrammetric Engineering \& Remote Sensing 79(11): 999-1014. DOI: 10.14358/PERS.79.11.999.

Schöpfer E., Lang S., 2006. Object Fate Analysis - a Virtual Overlay Method for the Categorisation of Object Transition and Object-Based Accuracy Assessment In: 1st International Conference on Object-Based Image Analysis (OBIA 2006). Salzburg.

Smith G.M., Morton R.D., 2010. Real World Objects in GEOBIA through the Exploitation of Existing Digital Cartography and Image Segmentation. Photogrammetric Engineering \& Remote Sensing 76(2): 163-171. DOI: 10.14358/ PERS.76.2.163.

Tiede D., Lang S., Albrecht F., Hölbling D., 2010. Object-Based Class Modeling for Cadastre-Constrained Delineation of Geo-Objects. Photogrammetric Engineering \& Remote Sensing 76(2): 193-202. DOI: 10.14358/PERS.76.2.193.

Varga OG., Szabó S., Túri Z., 2014. Efficiency Assessments of GEOBIA in Land Cover Analysis, NE Hungary. Bulletin of Environmental and Scientific Research.

Willhauck G., Schneider T., de Kok R., Ammer U., 2000. Comparison of Object Oriented Classification Techniques and Standard Image Analysis for the Use of Change Detection between SPOT Multispectral Satellite Images and Aerial Photos. ISPRS Archives XXXIII (Supplement B3): 214-221.

Xie F., Chen D., Meligrana J., 2013. Selecting Key Features for Remote Sensing Classification by Using Decision-Theoretic Rough Set Model. Photogrammetric Engineering $\mathcal{E}$ Remote Sensing 79(9): 787-797. 